Article

\title{
Theoretical Study on Magnetic Interaction in Pyrazole-Bridged Dinuclear Metal Complex: Possibility of Intramolecular Ferromagnetic Interaction by Orbital Counter-Complementarity
}

\author{
Takuya Fujii ${ }^{1}$, Yasutaka Kitagawa ${ }^{1,2, *} \mathbb{C}$, Kazuki Ikenaga ${ }^{1}$, Hayato Tada ${ }^{1}$, Iori Era ${ }^{1}$ and \\ Masayoshi Nakano $1,2,3,4, *$ (D) \\ 1 Department of Materials Engineering Science, Graduate School of Engineering Science, Osaka University, \\ Toyonaka, Osaka 560-8531, Japan; tfujii@cheng.es.osaka-u.ac.jp (T.F.); \\ kazuki.ikenaga@cheng.es.osaka-u.ac.jp (K.I.); hayato.tada@cheng.es.osaka-u.ac.jp (H.T.); \\ iori.era@cheng.es.osaka-u.ac.jp (I.E.) \\ 2 Center for Spintronics Research Network (CSRN), Graduate School of Engineering Science, \\ Osaka University, Toyonaka, Osaka 560-8531, Japan \\ 3 Quantum Information and Quantum Biology Division, Institute for Open and Transdisciplinary Research \\ Initiatives, Osaka University, Toyonaka, Osaka 560-8531, Japan \\ 4 Institute for Molecular Science, 38 Nishigo-Naka, Myodaiji, Okazaki 444-8585, Japan \\ * Correspondence: kitagawa@cheng.es.osaka-u.ac.jp (Y.K.); mnaka@cheng.es.osaka-u.ac.jp (M.N.)
}

Received: 31 December 2019; Accepted: 24 February 2020; Published: 26 February 2020

\begin{abstract}
A possibility of the intramolecular ferromagnetic (FM) interaction in pyrazole-bridged dinuclear $\mathrm{Mn}(\mathrm{II}), \mathrm{Fe}(\mathrm{II}), \mathrm{Co}(\mathrm{II})$, and $\mathrm{Ni}(\mathrm{II})$ complexes is examined by density functional theory (DFT) calculations. When azide is used for additional bridging ligand, the complexes indicate the strong antiferromagnetic (AFM) interaction, while the AFM interaction becomes very weak when acetate ligand is used. In the acetate-bridged complexes, an energy split of the frontier orbitals suggests the orbital counter-complementarity effect between the $d_{x y}$ orbital pair, which contributes to the FM interaction; however, a significant overlap of other d-orbital pairs also suggests an existence of the AFM interaction. From those results, the orbital counter-complementarity effect is considered to be canceled out by the overlap of other d-orbital pairs.
\end{abstract}

Keywords: pyrazole-bridged dinuclear metal complex; effective exchange integral (J); density functional theory (DFT); broken-symmetry (BS) method; orbital complementarity

\section{Introduction}

Since the discovery of single-molecule magnets (SMMs) [1-3], a huge number of studies have been devoted to finding the compounds with a higher blocking temperature $\left(T_{\mathrm{B}}\right)$. Because a blocking barrier height $\left(U_{\text {eff }}\right)$ is in proportion to $|D| S^{2}$, where $D$ and $S$ are magnetic anisotropy and spin size, respectively, a larger (negative) $D$ or larger $S$ is required to realize the higher $T_{B}$. In recent years, for example, lanthanide ions such as $\mathrm{Tb}$ (III) or $\mathrm{Dy}(\mathrm{III})$ have been introduced to enlarge $|D|$ values by increasing the magnetic anisotropy. An alternative way to realize the high- $T_{\mathrm{B}}$ compound is an introduction of a plural number of metal ions to increase the spin size $S$. Because it is usually difficult to align the metal ions in the ferromagnetic manner, sometimes, the ferrimagnetic interaction using different valencies such as $\mathrm{Mn}(\mathrm{IV}) / \mathrm{Mn}(\mathrm{III})$ has been utilized to increase the size of $S$ [3]. If we have rational and effective guidelines to align spins on each metal ion ferromagnetically, however, the size of $S$ is easily increased. The ferromagnetic interaction is often explained by the orbital degeneracy due to the orbital 
orthogonality. The orbital orthogonality has succeeded in the explanation of many ferromagnetic materials [4]. For example, in the Prussian blue analogues (PBA), which is one of the ferromagnetic materials, the orbital degeneracy originating in the orthogonality between $t_{2 \mathrm{~g}}$ and $e_{\mathrm{g}}$ orbitals causes the ferromagnetic interaction [5-8]. The orbital orthogonality found in such PBA analogues, however, requires the linearly aligned metal-ligand-metal structures, as well as the specific combination of metal ions such as $\mathrm{Cr}(\mathrm{III}) / \mathrm{Cr}(\mathrm{II})$, so that it is considered to have less degrees of freedom in molecular structures. On the other hand, it has been known that some heterogeneous bridging ligands between two $\mathrm{Cu}$ (II) ions make different contributions to the magnetic exchange interactions $[9,10]$. A pyrazole, which is a heterocyclic five-membered ring compound, is often used as a bridging ligand between two metal ions [9-12]. Kida, Okawa, and co-workers reported that pyrazole-bridged dinuclear-Cu(II) complexes with azide and acetate as counter bridging-ligands shown in Figure 1 exhibit anti-ferromagnetic (AFM) and ferromagnetic (FM) behavior, respectively $[9,10]$. They explained this phenomenon by an orbital complementarity/counter-complementarity that originates in the orbital interaction between $\mathrm{Cu}$ (II) and bridging-ligands. On the other hand, the theoretical studies with ab initio and density functional theory (DFT) calculations have been one of the powerful tools for the investigation of the effective exchange integrals $(J)$, especially for the polynuclear metal complexes [13-19]. Up to now, there have been only several papers that examine the exchange interactions of those complexes by theoretical calculations [14-18]; furthermore, those are devoted to elucidating the mechanism of the ferromagnetic interaction between two metal ions. The concept of the orbital counter-complementarity, however, predicts the ferromagnetic materials from differences in the phase of molecular orbitals between ligands and metals; therefore, it can be applied to the theoretical design of ferromagnetic molecules. As described below, it is considered that the magnetic interaction is not necessarily ferromagnetic, except for the $\mathrm{Cu}(\mathrm{II})$ complex, because of competition between the ferromagnetic interaction by orbital counter-complementarity and antiferromagnetic interaction by direct $\mathrm{d}-\mathrm{d}$ overlap. In this study, as the first step for the molecular design, we examine whether this concept can be applied to metal ions, except for $\mathrm{Cu}(\mathrm{II})$, by introducing them into the model structures. Here, we examine the high-spin species of divalent $3 \mathrm{~d}$ metal ions; $\mathrm{Mn}(\mathrm{II}), \mathrm{Fe}(\mathrm{II}), \mathrm{Co}(\mathrm{II})$, and $\mathrm{Ni}(\mathrm{II})$.

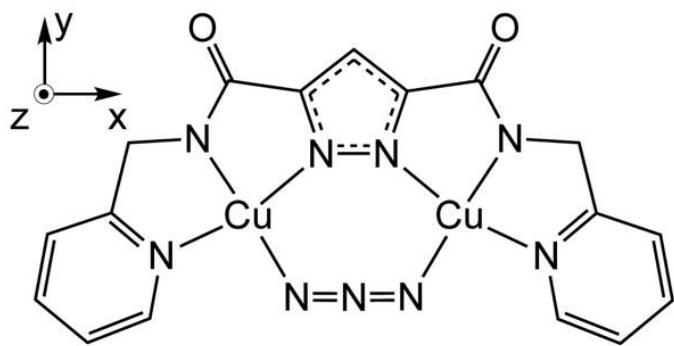

complex 1

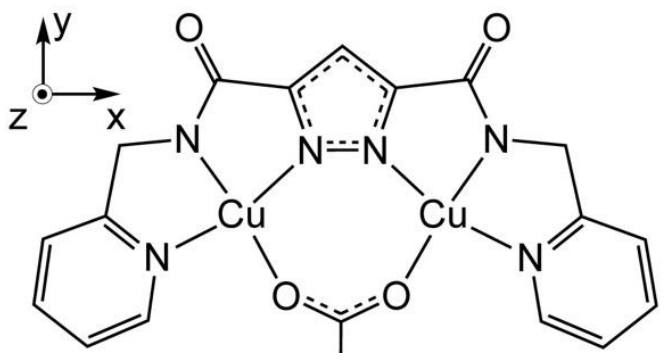

complex 2

Figure 1. Dinuclear $\mathrm{Cu}(\mathrm{II})$ complexes bridged by azide (complex 1) and acetate (complex 2) ligands.

\section{Theoretical Background}

\subsection{Orbital Complementarity and Counter-Complementarity}

The concept of the orbital complementarity and counter-complementarity is briefly explained here using the dinuclear copper(II) complexes illustrated in Figure $1[9,10]$. Because each $\mathrm{Cu}(\mathrm{II})$ ion has a spin in the $\mathrm{d}_{\mathrm{xy}}$ orbital, two $\mathrm{Cu}$ (II) ions in the complex form $\pi$-type symmetric bonding $\left(\varphi_{\mathrm{s}}\right)$ and anti-symmetric anti-bonding $\left(\varphi_{\mathrm{a}}\right)$ orbitals within the $x y$ plane, as illustrated in Figure 2. The metal-metal bonding and anti-bonding orbitals also interact with the bridging-ligand orbitals. The pyrazole $\left(\varphi_{\mathrm{pz}}\right)$ ligand, which provides an anti-symmetric coordination orbital, interacts with the anti-symmetric $\left(\varphi_{\mathrm{a}}\right)$ orbital and forms in-phase $\left(\varphi_{\mathrm{a}}+\varphi_{\mathrm{pz}}\right)$ and out-of-phase $\left(\varphi_{\mathrm{a}}-\varphi_{\mathrm{pz}}\right)$ orbitals. In the 
case of complex 1, the azide ligand orbital $\left(\varphi_{\mathrm{az}}\right)$ can interact with $\varphi_{\mathrm{a}}$ (Figure 2a), and the out-of-phase orbital $\left(\varphi_{\mathrm{a}-(\mathrm{pz}+\mathrm{az})}^{*}\right)$ becomes unstable, while the bonding-orbital $\varphi_{\mathrm{s}}$ does not interact with ligand orbitals. As a result, two spins belong to the lower $\varphi_{\mathrm{s}}$ rather than $\varphi_{\mathrm{a}-(\mathrm{pz}+\mathrm{az})^{\prime}}$, and thus the AFM state is predicted to become the ground state. On the other hand, in the case of complex $2, \varphi_{\mathrm{a}}$ and $\varphi_{\mathrm{s}}$ interact with pyrazole $\left(\varphi_{\mathrm{pz}}\right)$ and acetate $\left(\varphi_{\mathrm{ac}}\right)$, respectively. Consequently, the two formed out-of-phase orbitals, that is, $\varphi_{\mathrm{a}-\mathrm{pz}}^{*}$ and $\varphi_{\mathrm{s}-\mathrm{ac}}^{*}$, tend to be quasi-degenerate. Therefore, the FM state is predicted to become the ground state of complex 2 . Those explanations, however, assume an interaction among ligand orbitals and $\varphi_{\mathrm{a}}$ (and $\varphi_{\mathrm{s}}$ ) orbitals that consist of $\mathrm{d}_{\mathrm{xy}}$ of $\mathrm{Cu}(\mathrm{II})$. As mentioned above, we examine the high-spin species of $\mathrm{Mn}(\mathrm{II}), \mathrm{Fe}(\mathrm{II}), \mathrm{Co}(\mathrm{II})$, and $\mathrm{Ni}(\mathrm{II})$, because the low-spin species do not have spins in the $d_{x y}$ orbital. Because metal ions examined in this paper have more spins (e.g., $s=5 / 2,2,3 / 2$, and 1 for $\mathrm{Mn}(\mathrm{II}), \mathrm{Fe}(\mathrm{II}), \mathrm{Co}(\mathrm{II})$, and $\mathrm{Ni}(\mathrm{II})$, respectively), the direct overlap between other d-orbital pairs can contribute to the AFM interaction. In this sense, the relative stability between the FM and AFM states is predicted to be determined by a balance between the FM interaction via the orbital counter-complementarity caused by $\mathrm{d}_{\mathrm{xy}}$ and the AFM interaction via direct overlap of other orbitals.

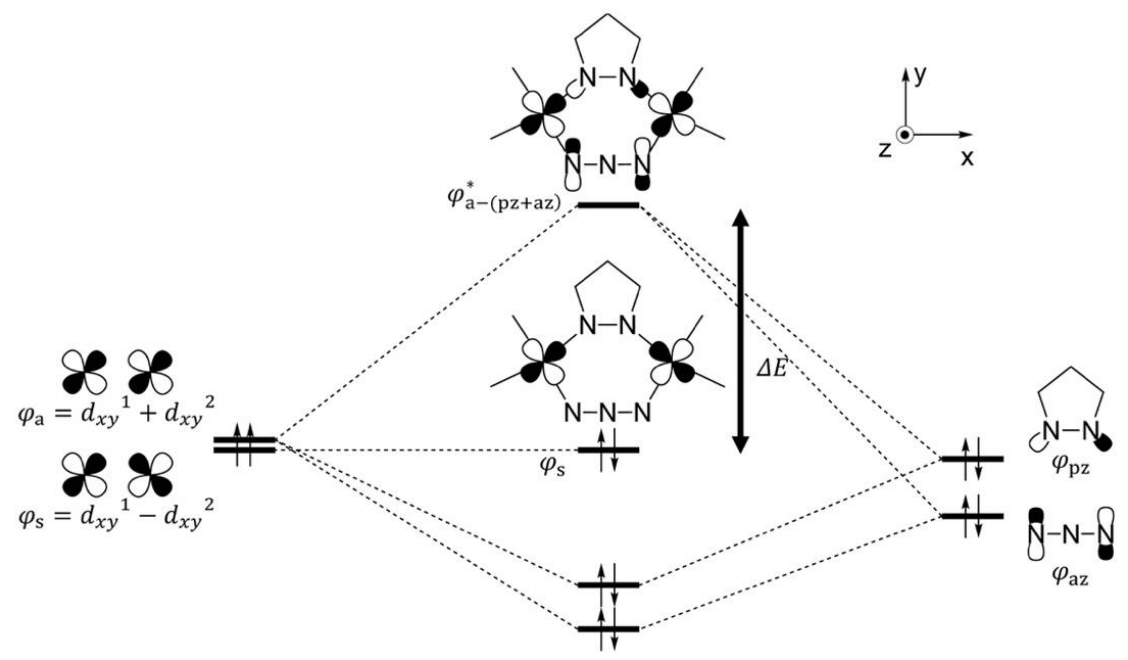

(a)

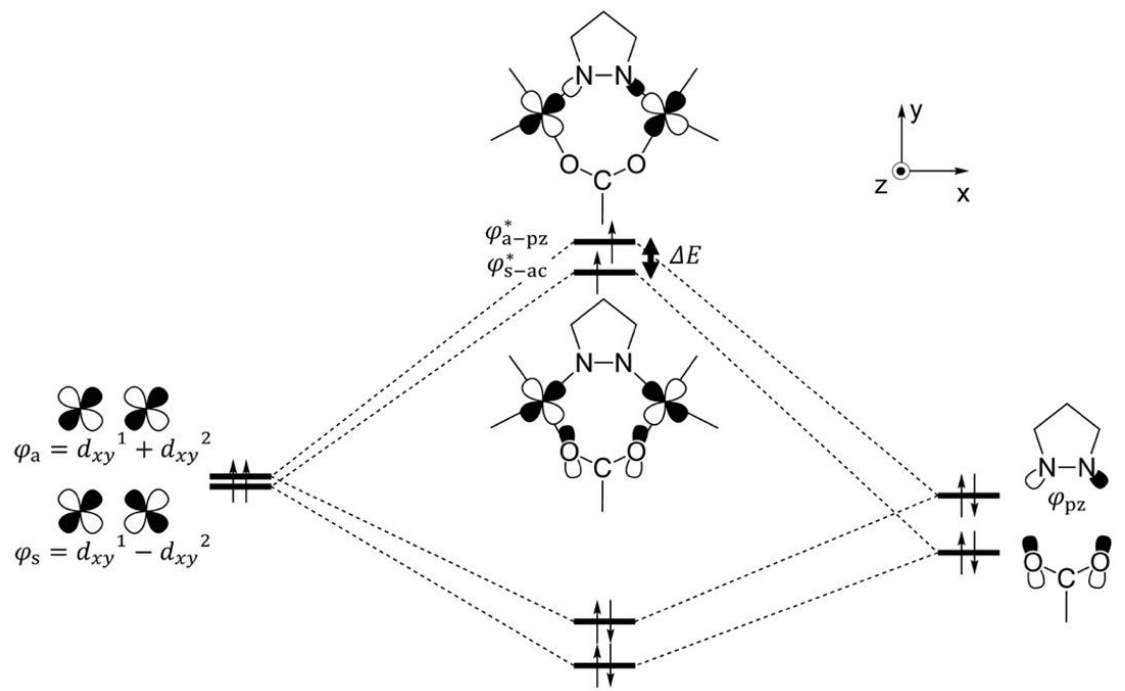

(b)

Figure 2. Schematic representation of orbital interactions for (a) complementarity and (b) counter-complementarity found in complexes $\mathbf{1}$ and $\mathbf{2}$, respectively. 


\subsection{Computational Models}

On the basis of the reported structures of two complexes $\mathbf{1}$ and 2 illustrated in Figure 1, we constructed model structures by substituting $\mathrm{Mn}(\mathrm{II}), \mathrm{Fe}(\mathrm{II}), \mathrm{Co}(\mathrm{II})$, and $\mathrm{Ni}(\mathrm{II})$ ions. In order to conduct a systematic analysis, we assume an octahedral coordination for all models and the axial positions of metal ions are capped by ammonia molecules that provide a moderate ligand field, as illustrated in Figure 3a. For comparison, $\mathrm{Cr}(\mathrm{II})$ complexes that do not have electrons in $\mathrm{d}_{\mathrm{xy}}$ orbitals are also examined (Figure $3 b)$.

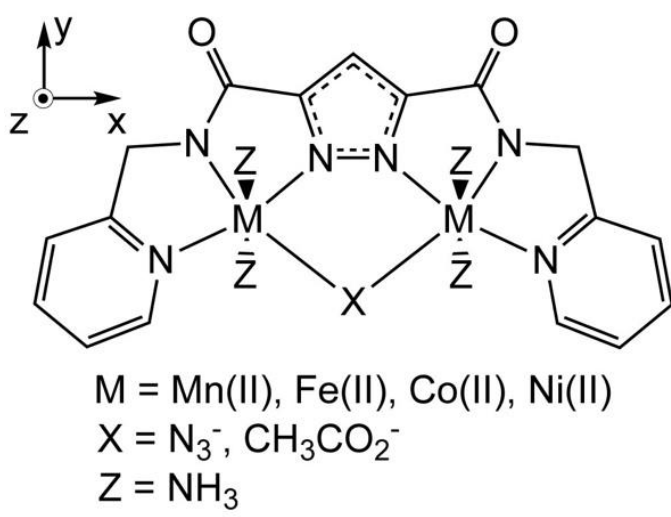

(a)

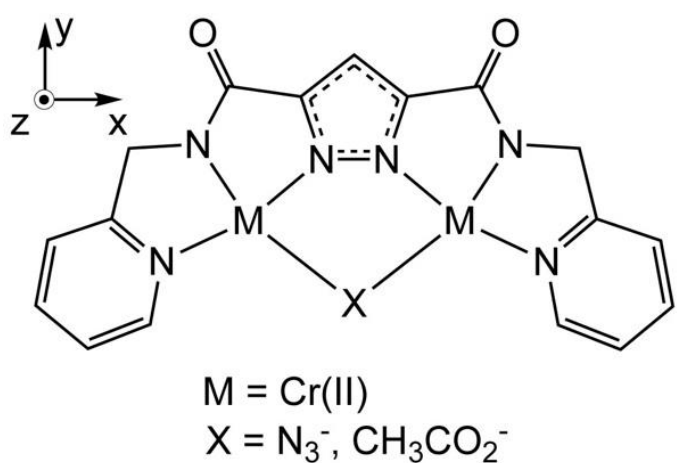

(b)

Figure 3. Illustration for pyrazole-bridged dinuclear metal complexes substituted by $\mathrm{Mn}(\mathrm{II}), \mathrm{Fe}(\mathrm{II})$, $\mathrm{Co}(\mathrm{II}), \mathrm{Ni}(\mathrm{II})$ ions (a), and $\mathrm{Cr}(\mathrm{II})$ ions (b). Note that a square planar structure is assumed for the $\mathrm{Cr}(\mathrm{II})$ complexes because the octahedral structure is not obtained by the geometry optimization.

\subsection{Computational Details}

For all calculations, we employed the broken-symmetry (BS) method [20] using the B3LYP functional [21] with the 6-31G* [22] basis set to obtain the spin-polarized electronic structures. The model structures were, at first, fully optimized and the optimized geometries were confirmed not to have any imaginary frequencies. In order to investigate the difference in the structures between the AFM and FM states, we performed the geometry optimization for both states. At each optimized geometry, the intramolecular magnetic interaction between two metal ions was discussed based on the effective exchange integral $(J)$ values calculated by the Yamaguchi equation $[23,24]$,

$$
J=\frac{E^{\mathrm{AFM}}-E^{\mathrm{FM}}}{\left\langle S^{2}\right\rangle^{\mathrm{FM}}-\left\langle S^{2}\right\rangle^{\mathrm{AFM}}}
$$

where $E^{\mathrm{X}}$ and $\left\langle S^{2}\right\rangle^{\mathrm{X}}$ denote total energies and $\left\langle S^{2}\right\rangle$ values of spin state $\mathrm{X}(\mathrm{X}=\mathrm{FM}$ and $\mathrm{AFM})$. All calculations were performed in the gas phase using Gaussian09 [25].

\section{Results and Discussion}

\subsection{Optimized Structures and Calculated J Values}

The optimized Cartesian coordinates of model structures for both AFM and FM states are summarized in Table S1 in Supplementary Materials. The calculated total energies and $\left\langle S^{2}\right\rangle$ values are summarized in Tables S2 and S3 in Supplementary Materials. We also confirm that the Fe(II) and Co(II) complexes energetically prefer the high-spin metal species rather than the low-spin species, as summarized in Tables S4 and S5 in Supplementary Materials. In addition, the stability of those model complexes is examined by roughly estimating the stabilization energies, as summarized in Table S6 in Supplementary Materials. The results indicate the possibility of existence of all model structures. 
Calculated $J$ values at the optimized geometry are summarized in Table 1. All models show negative $J$ values even at the optimized structures for the FM states, indicating that the AFM exchange interaction between the metal ions is dominant even in the acetate-bridged complexes, in contrast to the $\mathrm{Cu}$ (II) complexes [17]. The azide-bridged complexes, however, exhibit significantly stronger AFM interaction, while the calculated $J$ values of those acetate-bridged complexes are close to zero, indicating the small energy gap between the AFM and FM states. The result suggests that the orbital complementarity/counter-complementarity affects the magnetic interaction, like in $\mathrm{Cu}(\mathrm{II})$ complexes.

Table 1. Calculated $J$ values at the optimized structures, where $J_{\mathrm{AFM}}$ and $J_{\mathrm{FM}}$ represent calculated $J$ values with the antiferromagnetic (AFM) and ferromagnetic (FM) structures, respectively.

\begin{tabular}{|c|c|c|c|c|}
\hline $\mathbf{M}$ & $X$ & $J_{\mathrm{AFM}} / \mathrm{cm}^{-1}$ & $J_{\mathrm{FM}} / \mathrm{cm}^{-1}$ & $\operatorname{Exptl}{ }^{b} / \mathrm{cm}^{-1}$ \\
\hline \multirow{2}{*}{$\mathrm{Cr}(\mathrm{II})$} & $\mathrm{N}_{3}^{-}$ & -8.9 & -8.3 & \\
\hline & $\mathrm{CH}_{3} \mathrm{CO}_{2}^{-}$ & -3.2 & -3.1 & \\
\hline \multirow{2}{*}{$\mathrm{Mn}(\mathrm{II})$} & $\mathrm{N}_{3}^{-}$ & -9.1 & -8.1 & \\
\hline & $\mathrm{CH}_{3} \mathrm{CO}_{2}^{-}$ & -0.3 & -0.2 & \\
\hline \multirow{2}{*}{$\mathrm{Fe}(\mathrm{II})$} & $\mathrm{N}_{3}^{-}$ & -13.1 & -11.3 & \\
\hline & $\mathrm{CH}_{3} \mathrm{CO}_{2}^{-}$ & -1.1 & -1.0 & \\
\hline \multirow{2}{*}{$\mathrm{Co}(\mathrm{II})$} & $\mathrm{N}_{3}^{-}$ & -26.1 & -23.0 & \\
\hline & $\mathrm{CH}_{3} \mathrm{CO}_{2}^{-}$ & -2.0 & -0.1 & \\
\hline \multirow{2}{*}{$\mathrm{Ni}(\mathrm{II})$} & $\mathrm{N}_{3}^{-}$ & -74.2 & -33.1 & \\
\hline & $\mathrm{CH}_{3} \mathrm{CO}_{2}^{-}$ & -3.2 & -3.1 & \\
\hline \multirow{2}{*}{$\mathrm{Cu}(\mathrm{II})^{\mathrm{a}}$} & $\mathrm{N}_{3}^{-}$ & -436 & -364 & -371 \\
\hline & $\mathrm{CH}_{3} \mathrm{CO}_{2}^{-}$ & 13.5 & 23.0 & $>8.9$ \\
\hline
\end{tabular}

${ }^{\mathrm{a}}$ Calculated values in the work of [17]. ${ }^{\mathrm{b}}$ Experimental values in the work of [9].

\subsection{Orbital Energy Difference}

Next, we examined the energy gap between the symmetric and antisymmetric orbitals $(\Delta E)$, which is the origin of the concept of orbital complementarity, as illustrated in Figure 2. Here, $\Delta E$ is defined as follows,

$$
\Delta \mathrm{E}=\left\{\begin{array}{cc}
\left|\mathrm{E}\left(\varphi_{\mathrm{a}-(\mathrm{pz}+\mathrm{az})}^{*}\right)-\mathrm{E}\left(\varphi_{\mathrm{s}}\right)\right| & X=\mathrm{N}_{3}^{-} \\
\left|\mathrm{E}\left(\varphi_{\mathrm{a}-\mathrm{pz}}^{*}\right)-\mathrm{E}\left(\varphi_{\mathrm{s}-\mathrm{ac}}^{*}\right)\right| & X=\mathrm{CH}_{3} \mathrm{CO}_{2}^{-}
\end{array}\right.
$$

If $\Delta E$ value is negligible, those two orbitals shown in Figure 2 are quasi-degenerate and the FM state becomes stable owing to Hund's rule. As seen from Table 2, $\Delta E$ values of the azide-bridged complexes are larger than those of the acetate-bridged complexes. For example, the $\Delta E$ value of the acetate-bridged $\mathrm{Mn}(\mathrm{II})$ complex is $0.06 \mathrm{eV}$. $\Delta E$ values of the acetate-bridged complexes are shown to be small as compared with that of the $\mathrm{Cu}$ (II) complex [17]; therefore, the FM state is expected to become stable. However, their $J$ values are found to be small, but still negative. This result indicates another mechanism to stabilize the AFM state, suggesting the overlap between metal ions via other d-orbitals.

\subsection{Natural Orbital Analyses}

In order to explain the AFM interaction of the acetate-bridged complexes, spin-unrestricted natural orbital (UNO) analysis is performed for the AFM state of each complex. The UNOs are obtained by diagonalizing the first order density matrix, and the occupation number of orbital $i\left(n_{i}\right)$ is related to the overlap between $\alpha$ and $\beta$ orbitals $\left(T_{i}\right)$ as

$$
T_{i}=n_{i}-1
$$

If $n_{i}$ is close to 1.0 , then the two electrons in the corresponding $\alpha$ and $\beta$ orbitals are spatially polarized, indicating that spins on the metal ions are almost localized there, that is, the fully spin-polarized state. On the other hand, $n_{i}$ should be equal to 2.0 if those are fully overlapped, and spins disappear. The calculated occupation numbers of magnetic orbitals are summarized in 
Table 3 and corresponding natural orbitals are depicted in Figures S1-S8. Although the $d_{x y}$ orbitals of which the occupation numbers are close to 1.0 are spin-polarized, they still have significant overlap. In addition, other metal d-orbital pairs also have larger overlaps that contribute to the AFM interaction with the direct $d$-d overlap. For example, the overlaps between $d_{z x}$ orbitals that are in a range of $0.013-0.025$ is found to be comparable to those of $d_{x y}$ in the acetate-bridged complexes. As a result, those orbital overlaps between those d-orbital pairs are considered to contribute to the stabilization of the AFM state. In those complexes, metal ions and bridging ligands are in the same plane; therefore, the metal-metal distance is a clue to consider the magnetic interaction. As summarized in Table S7 in Supplementary Information, the metal-metal distances depend on the metal species; however, they do not show a significant relationship between the overlap and the distances. It suggests that such a small overlap does not change the molecular structure, but only the magnetic interaction.

Table 2. Energy gap between the symmetric and antisymmetric combinations of the magnetic orbitals $(\Delta E)$ in the FM state.

\begin{tabular}{ccc}
\hline $\mathbf{M}$ & $\mathbf{X}$ & $\Delta E / \mathbf{e V}$ \\
\hline \multirow{2}{*}{$\mathrm{Mn}(\mathrm{II})$} & $\mathrm{N}_{3}^{-}$ & 0.42 \\
& $\mathrm{CH}_{3} \mathrm{CO}_{2}{ }^{-}$ & 0.06 \\
$\mathrm{Fe}(\mathrm{II})$ & $\mathrm{N}_{3}{ }^{-}$ & 0.40 \\
& $\mathrm{CH}_{3} \mathrm{CO}_{2}{ }^{-}$ & 0.07 \\
$\mathrm{Co}(\mathrm{II})$ & $\mathrm{N}_{3}{ }^{-}$ & 0.29 \\
& $\mathrm{CH}_{3} \mathrm{CO}_{2}{ }^{-}$ & 0.12 \\
$\mathrm{Ni}(\mathrm{II})$ & $\mathrm{N}_{3}^{-}$ & 0.20 \\
& $\mathrm{CH}_{3} \mathrm{CO}_{2}^{-}$ & 0.18 \\
$\mathrm{Cu}(\mathrm{II})^{\mathrm{a}}$ & $\mathrm{N}_{3}^{-}$ & 1.33 \\
& $\mathrm{CH}_{3} \mathrm{CO}_{2}{ }^{-}$ & 0.60
\end{tabular}

a In the work of [17]. Note that the values are calculated by UBHandHLYP/6-31G* level of theory, and thus overestimated.

Table 3. Occupation numbers $(n)$ of unrestricted natural orbitals (UNOs) for magnetic orbitals of model complexes, where dominant d-orbitals in each UNO are expressed in square parentheses.

\begin{tabular}{|c|c|c|c|c|c|c|}
\hline $\mathbf{M}$ & $X$ & HONO & HONO-1 & HONO-2 & HONO-3 & HONO-4 \\
\hline \multirow[t]{2}{*}{ Mn(II) } & $\mathrm{N}_{3}^{-}$ & {$\left[\begin{array}{c}1.002 \\
{\left[d_{x^{2}-y^{2}}\right.}\end{array}\right]$} & $1.011\left[\mathrm{~d}_{\mathrm{yz}}\right]$ & $1.012\left[\mathrm{~d}_{\mathrm{z}^{2}}\right]$ & $1.025\left[\mathrm{~d}_{\mathrm{zx}}\right]$ & $1.093\left[\mathrm{~d}_{\mathrm{xy}}\right]$ \\
\hline & $\mathrm{CH}_{3} \mathrm{CO}_{2}^{-}$ & $1.006\left[\mathrm{~d}_{\mathrm{z}^{2}}\right]$ & $\begin{array}{c}1.007 \\
\mathrm{~d}_{\mathrm{x}^{2}-\mathrm{y}^{2}}\end{array}$ & $1.013\left[\mathrm{~d}_{\mathrm{yz}}\right]$ & $1.017\left[\mathrm{~d}_{\mathrm{xy}}\right]$ & $1.018\left[\mathrm{~d}_{\mathrm{zx}}\right]$ \\
\hline \multirow{2}{*}{$\mathrm{Fe}(\mathrm{II})$} & $\mathrm{N}_{3}^{-}$ & $1.009\left[\mathrm{~d}_{\mathrm{yz}}\right]$ & $1.012\left[\mathrm{~d}_{\mathrm{z}^{2}}\right]$ & $1.021\left[\mathrm{~d}_{\mathrm{zx}}\right]$ & $1.087\left[\mathrm{~d}_{\mathrm{xy}}\right]$ & \\
\hline & $\mathrm{CH}_{3} \mathrm{CO}_{2}{ }^{-}$ & {$\left[\begin{array}{c}1.004 \\
\mathrm{~d}_{\mathrm{x}^{2}-\mathrm{y}^{2}}\end{array}\right]$} & $1.009\left[\mathrm{~d}_{\mathrm{yz}}\right]$ & $1.016\left[\mathrm{~d}_{\mathrm{zx}}\right]$ & $1.019\left[\mathrm{~d}_{\mathrm{xy}}\right]$ & \\
\hline \multirow{2}{*}{$\mathrm{Co}(\mathrm{II})$} & $\mathrm{N}_{3}^{-}$ & $1.011\left[\mathrm{~d}_{\mathrm{z}^{2}}\right]$ & $1.023\left[\mathrm{~d}_{\mathrm{zx}}\right]$ & $1.094\left[\mathrm{~d}_{\mathrm{xy}}\right]$ & & \\
\hline & $\mathrm{CH}_{3} \mathrm{CO}_{2}^{-}$ & $1.007\left[\mathrm{~d}_{\mathrm{z}^{2}}\right]$ & $1.013\left[\mathrm{~d}_{\mathrm{zx}}\right]$ & $1.022\left[\mathrm{~d}_{\mathrm{xy}}\right]$ & & \\
\hline \multirow{2}{*}{$\mathrm{Ni}(\mathrm{II})$} & $\mathrm{N}_{3}^{-}$ & $1.019\left[\mathrm{~d}_{\mathrm{z}^{2}}\right]$ & $1.113\left[\mathrm{~d}_{\mathrm{xy}}\right]$ & & & \\
\hline & $\mathrm{CH}_{3} \mathrm{CO}_{2}^{-}$ & $1.012\left[\mathrm{~d}_{\mathrm{z}^{2}}\right]$ & $1.029\left[\mathrm{~d}_{\mathrm{xy}}\right]$ & & & \\
\hline \multirow{2}{*}{$\mathrm{Cu}(\mathrm{II})^{\mathrm{a}}$} & $\mathrm{N}_{3}^{-}$ & $1.188\left[\mathrm{~d}_{\mathrm{xy}}\right]$ & & & & \\
\hline & $\mathrm{CH}_{3} \mathrm{CO}_{2}^{-}$ & $1.002\left[\mathrm{~d}_{\mathrm{xy}}\right.$ & & & & \\
\hline
\end{tabular}

In order to confirm the effects of the orbital complementarity, counter-complementarity, and direct overlap, we examined the $\mathrm{Cr}$ (II) complexes. As the high-spin Mn(II) ion has $d^{5}$ configuration, each d-orbital is filled by one electron in the complexes, while a $\mathrm{d}_{\mathrm{xy}}$ orbital is not occupied in the case of the $\mathrm{Cr}$ (II) complex ( $d^{4}$ configuration) owing to the strong ligand field by surrounding ligands. A difference in the calculated $J$ values between azide- and acetate-bridged complexes for the $\mathrm{Cr}$ (II) complexes is found to be less than that for the $\mathrm{Mn}(\mathrm{II})$ complexes. This contrast suggests that the 
orbital counter-complementarity effect contributes to a decrease of the energy gap between the AFM and FM states. In addition, calculated $J$ values of the azide-bridged $\mathrm{Mn}$ (II) and $\mathrm{Cr}$ (II) complexes are almost the same; nevertheless, the acetate-bridged $\mathrm{Cr}$ (II) complex shows a negative value about $3 \mathrm{~cm}^{-1}$ smaller than the $\mathrm{Mn}$ (II) complex. An electron configuration of the $\mathrm{Cr}$ (II) complexes can be obtained by eliminating electrons from $\mathrm{d}_{\mathrm{xy}}$ orbitals of the $\mathrm{Mn}$ (II) complexes; therefore, roughly speaking, the difference is predicted to originate in the stabilization of the FM state caused by the degeneracy in $\varphi_{\mathrm{a}-\mathrm{pz}}^{*}$ and $\varphi_{\mathrm{s}-\mathrm{ac}}^{*}$, that is, orbital counter-complementarity. From those results, it is predicted that the FM interaction via the counter-complementarity is canceled by the AFM interaction via overlap of other d-orbitals in those complexes.

Finally, we consider a possibility of an end-on type coordination of the azide complex. It has been reported that the azide ligand can bridge two metal ions with the end-on type manner as well as the side-on type, which is considered above [26,27]. We performed geometry optimization of the dinuclear $\mathrm{Cu}$ (II) complex for the end-on type structure, which is summarized in Table S8 in Supplementary Information. The total energies of the side-on and end-on type structures that are summarized in Table S9 in Supplementary Information indicate the side-on type is significantly stable in comparison with the end-on type. Therefore, we did not mention the end-on type structures of other metal complexes in this manuscript, although the end-on type induces the ferromagnetic interaction.

\section{Conclusions}

In this paper, we examine the possibility of the intramolecular FM interaction in pyrazole-bridged dinuclear $\mathrm{Mn}(\mathrm{II}), \mathrm{Fe}(\mathrm{II}), \mathrm{Co}(\mathrm{II})$, and $\mathrm{Ni}(\mathrm{II})$ complexes. We confirmed that the azide-bridged complexes indicate the strong AFM interaction, while the acetate-bridged complexes exhibit a very weak AFM interaction. These results suggest that the counter-complementarity effect, which contributes to the FM interaction, competes with the AFM interaction caused by overlap of other d-orbital pairs. Conversely, there is the possibility that these $3 \mathrm{~d}$ metal complexes exhibit an FM interaction if one can decrease the overlap. For that purpose, a rational designing guideline based on the quantum chemical calculation is considered to be effective for modifying the species of substituents and their substitution positions [28].

Supplementary Materials: The following are available online at http://www.mdpi.com/2312-7481/6/1/10/s1, Table S1: Optimized cartesian coordinates (Å) of acetate bridged dinuclear Ni(II) complex; Table S2: Calculated total energies and $\left\langle S^{2}\right\rangle$ values at AFM structures; Table S3: Calculated total energies and $\left\langle S^{2}\right\rangle$ values at FM structures; Table S4: Calculated total energies and $\left\langle S^{2}\right\rangle$ values of low-spin Fe(II) $(s=0)$ complexes; Table S5: Calculated total energies and $\left\langle S^{2}\right\rangle$ values of low-spin $\operatorname{Co}(\mathrm{II})(s=1 / 2)$ complexes; Table S6: Stabilization energy $(\mathrm{kJ} / \mathrm{mol})$ for each complex; Table S7: Metal-metal distances $(\AA)$ in each complex; Table S8: Optimized cartesian coordinates $(\AA)$ of end-on azide bridged dinuclear $\mathrm{Cu}(\mathrm{II})$ complex; Table S9: Calculated total energies and $\left\langle\mathrm{S}^{2}\right\rangle$ values at $\mathrm{AFM}$ structures for dinuclear $\mathrm{Cu}(\mathrm{II})$ complex with side-on and end-on type azide bridges; Figure S1: Calculated natural orbitals of magnetic orbitals for acetate-bridged Mn(II) complex; Figure S2: Calculated natural orbitals of magnetic orbitals for acetate-bridged Fe(II) complex; Figure S3: Calculated natural orbitals of magnetic orbitals for acetate-bridged Co(II) complex; Figure S4: Calculated natural orbitals of magnetic orbitals for acetate-bridged Ni(II) complex; Figure S5: Calculated natural orbitals of magnetic orbitals for azide-bridged $\mathrm{Mn}(\mathrm{II})$ complex; Figure S6: Calculated spin-unrestricted natural orbitals of magnetic orbitals for azide-bridged Fe(II) complex; Figure S7: Calculated spin-unrestricted natural orbitals of magnetic orbitals for azide-bridged Co(II) complex; Figure S8: Calculated spin-unrestricted natural orbitals of magnetic orbitals for azide-bridged $\mathrm{Ni}(\mathrm{II})$ complex.

Author Contributions: Y.K. and T.F. designed the study and wrote the paper. K.I., H.T., and I.E. contributed calculations. M.N. organized the study. All authors have read and agreed to the published version of the manuscript.

Funding: This work was supported by Grant-in-Aid for Scientific Research (KAKENHI) (Nos. 19K05401, 26410093, and JP18H01943) from Japan Society for the Promotion of Science (JSPS). This work was also performed under the Inter-University Cooperative Research Program of the Institute for Materials Research, Tohoku University (Proposal No. 19K0061).

Conflicts of Interest: The authors declare no conflict of interest. 


\section{References}

1. Caneschi, A.; Gatteschi, D.; Sessoli, R.; Barra, A.L.; Brunel, L.C.; Guillot, M. Alternating current susceptibility, high field magnetization, and millimeter band EPR evidence for a ground $\mathrm{S}=10$ state in $\left[\mathrm{Mn}_{12} \mathrm{O}_{12}\left(\mathrm{CH}_{3} \mathrm{COO}\right)_{16}\left(\mathrm{H}_{2} \mathrm{O}\right)_{4}\right] \cdot 2 \mathrm{CH}_{3} \mathrm{COOH} \cdot 4 \mathrm{H}_{2} \mathrm{O}$. J. Am. Chem. Soc. 1992, 113, 5873-5874. [CrossRef]

2. Sessoli, R.; Gatteschi, D.; Caneschi, A.; Novak, M.A. Magnetic bistability in a metal-ion cluster. Nature 1993, 365, 141-143. [CrossRef]

3. Christou, G.; Gatteschi, D.; Hendrickson, D.N.; Sessoli, R. Single-Molecule Magnets. In MRS Bulletin; Cambridge University Press: Cambridge, UK, 2000; Volume 25, pp. 66-71.

4. Oshio, H.; Nihei, M.; Yoshida, A.; Nojiri, H.; Nakano, M.; Yamaguchi, A.; Karaki, Y.; Ishimoto, H. A Dinuclear MnIII-CuIISingle-Molecule Magnet. Chem. Euro. J. 2005, 11, 843-848. [CrossRef] [PubMed]

5. Gadet, V.; Mallah, T.; Castro, I.; Verdaguer, M.; Veillet, P. High-T $\mathrm{C}_{\mathrm{C}}$ molecular-based magnets: A ferromagnetic bimetallic chromium(III)-nickel(II) cyanide with $\mathrm{T}_{\mathrm{C}}=90 \mathrm{~K}$. J. Am. Chem. Soc. 1992, 114, 9213-9214. [CrossRef]

6. Mallah, T.; Thiébaut, S.; Verdaguer, M.; Veillet, P. High-T $\mathrm{C}_{\mathrm{c}}$ Molecular-Based Magnets: Ferrimagnetic Mixed-Valence Chromium(III)-Chromium(II) Cyanides with $\mathrm{T}_{\mathrm{c}}$ at 240 and 190 Kelvin. Science 1993, 262, 1554-1557. [CrossRef] [PubMed]

7. Tokoro, H.; Ohkoshi, S. Novel magnetic functionalities of Prussian blue analogs. Dalton Trans. 2011, 40, 6825-6833. [CrossRef] [PubMed]

8. Baker, M.L.; Kitagawa, Y.; Nakamura, T.; Tazoe, K.; Narumi, Y.; Kotani, Y.; Iijima, F.; Newton, G.N.; Okumura, M.; Oshio, H.; et al. X-ray Magnetic Circular Dichroism Investigation of the Electron Transfer Phenomena Responsible for Magnetic Switching in a Cyanide-Bridged [CoFe] Chain. Inorg. Chem. 2013, 52, 13956-13962. [CrossRef] [PubMed]

9. Kamiusuki, T.; Okawa, H.; Kitaura, E.; Koikawa, M.; Matsumoto, N.; Kida, S.; Oshio, H. Binuclear copper(II) complexes of new dinucleating ligands with a pyrazolate group as an endogenous bridge. Effects of exogenous azide and acetate bridges on magnetic properties. J. Chem. Soc. Dalton Trans. 1989, 2077-2081. [CrossRef]

10. Nishida, Y.; Kida, S. An Important Factor Determining the Significant Difference in Antiferromagnetic Interactions between Two Homologous ( $\mu$-Alkoxo)( $\mu$-pyrazolato- $\left.N, N^{\prime}\right)$ dicopper(II) Complexes. Inorg. Chem. 1988, 27, 447-452. [CrossRef]

11. Behle, L.; Neuburger, M.; Zehnder, M.; Kaden, T.A. Metal Complexes with Macrocyclic Ligands. Part XXXIX. Mono- and binuclear copper(II) complexes of a bridging bis[1,4,7-triazacyclononane]. Helv. Chim. Acta 1995, 78, 693-702. [CrossRef]

12. Meyer, F.; Beyreuther, S.; Heinze, K.; Zsolnai, L. Dinuclear Cobalt(II) Complexes of Pyrazole Ligands with Chelating Side Arms. Eur. J. Inorg. Chem. 1997, 130, 605-613. [CrossRef]

13. Pons, J.; López, X.; Benet, E.; Casabó, J.; Teixidor, F.; Sánchez, F.J. Dinuclear $\mu$-pyrazole nickel(II), cobalt(II), cadmium(II) and zinc(II) complexes with dinucleating pyrazole-derived ligands. Polyhedron 1990, 23, 2839-2845. [CrossRef]

14. Kitagawa, Y.; Saito, T.; Yamaguchi, K. Approximate Spin Projection for Broken-Symmetry Method and Its Application. In Symmetry (Group Theory) and Mathematical Treatment in Chemistry; Akitsu, T., Ed.; IntechOpen: London, UK, 2018. [CrossRef]

15. Tugrul Zeyrek, C. Importance of Orbital Complementarity in Spin Coupling through Two Different Bridging Groups in Dicopper(II) Complexes of Endogenous Alkoxo Bridging Ligand with Exogenous Carboxylate: Ab-initio and Semi-Empirical Calculations. Z. Naturforsch 2007, 62, 409-416. [CrossRef]

16. Wang, L.-L.; Sun, Y.-M.; Qui, Z.-N.; Liu, C.-B. Magnetic Interactions in Two Heterobridged Dinuclear Copper(II) Complexes: Orbital Complementarity or Countercomplementarity? J. Phys. Chem. A 2008, 112, 8418-8422. [CrossRef] [PubMed]

17. Miyagi, K.; Kitagawa, Y.; Asaoka, M.; Teramoto, R.; Natori, Y.; Saito, T.; Nakano, M. Theoretical study of magnetic interaction in pyrazole-bridged dinuclear Cu(II) complex. Polyhedron 2017, 136, 132-135. [CrossRef]

18. Kachi-Terajima, C.; Ishii, R.; Tojo, Y.; Fukuda, M.; Kitagawa, Y.; Asaoka, M.; Miyasaka, H. Ferromagnetic Exchange Coupling in a Family of Mn ${ }^{\mathrm{III}}$ Salen-Type Schiff-Base Out-of-Plane Dimers. J. Phys. Chem. C 2017, 121, 12454-12468. [CrossRef]

19. Wang, L.-L.; Sun, Y.-M.; Gao, J.; Lin, X.-J.; Liu, C.-B. Insights into the control of magnetic coupling in the $\mathrm{Mn}_{4}{ }^{\mathrm{III}}$ complex: From ferromagnetic to antiferromagnetic. Dalton Trans. 2010, 39, 10249-10255. [CrossRef] 
20. Fukutome, H. The Unrestricted Hartree-Fock Theory of Chemical Reactions. I: The Electronic Instabilities in the Chemical Reactions and the Solutions of the Unrestricted SCF LCAO MO Equation for the Homopolar Two-Center Two-Electron System. Prog. Theoret. Phys. 1972, 47, 1156-1180. [CrossRef]

21. Becke, A. Density-functional thermochemistry. III. The role of exact exchange. J. Chem. Phys. 1993, 98, 5648-5652. [CrossRef]

22. Ditchfield, R.; Hehre, W.J.; Pople, J.A. Self-Consistent Molecular Orbital Methods. IX. Extended Gaussian-type basis for molecular-orbital studies of organic molecules. J. Chem. Phys. 1971, 54, 724-728. [CrossRef]

23. Yamaguchi, K.; Fukui, H.; Fueno, T. Molecular orbital (MO) theory for magnetically interacting organic compounds. Ab-initio MO calculations of the effective exchange integrals for cyclophane-type carbene dimers. Chem. Lett. 1986, 15, 625-628. [CrossRef]

24. Soda, T.; Kitagawa, Y.; Onishi, T.; Takano, Y.; Shigeta, Y.; Nagao, H.; Yoshioka, Y.; Yamaguchi, K. Ab initio computations of effective exchange integrals for $\mathrm{H}-\mathrm{H}, \mathrm{H}-\mathrm{He}-\mathrm{H}$ and $\mathrm{Mn}_{2} \mathrm{O}_{2}$ complex: Comparison of broken-symmetry approaches. Chem. Phys. Lett. 2000, 319, 223-230. [CrossRef]

25. Frisch, M.J.; Trucks, G.W.; Schlegel, H.B.; Scuseria, G.E.; Robb, M.A.; Cheeseman, J.R.; Scalmani, G.; Barone, V.; Mennucci, B.; Petersson, G.A.; et al. Gaussian 09, Revision C.01; Gaussian, Inc.: Wallingford, CT, USA, 2009.

26. Yoon, J.H.; Ryu, D.W.; Kim, H.C.; Yoon, S.W.; Suh, B.J.; Hong, C.S. An End-On Azide-Bridged Antiferromagnetic Single-Chain Magnet Involving Spin Canting and Field-Induced Two-Step Magnetic Transitions. Chem. Enro. J. 2009, 15, 3661-3665. [CrossRef] [PubMed]

27. Ge, C.-H.; Cui, A.-L.; Ni, Z.-H.; Jiang, Y.-B.; Zhang, L.-F.; Ribas, J.; Kou, H.-Z. $\mu_{1,1}$-Azide-Bridged Ferromagnetic $\mathrm{Mn}^{\mathrm{III}}$ Dimer with Slow Relaxation of Magnetization. Inorg. Chem. 2006, 45, 4883-4885. [CrossRef] [PubMed]

28. Natori, Y.; Kitagawa, Y.; Aoki, S.; Teramoto, R.; Tada, H.; Era, I.; Nakano, M. Quantum chemical design guidelines for absorption and emission color tuning of $f a c-\operatorname{Ir}(\mathrm{ppy})_{3}$ complexes. Molecules 2018, $23,577$. [CrossRef] [PubMed]

(C) 2020 by the authors. Licensee MDPI, Basel, Switzerland. This article is an open access article distributed under the terms and conditions of the Creative Commons Attribution (CC BY) license (http://creativecommons.org/licenses/by/4.0/). 